\title{
Report for Development of a Census Array and Evaluation of the Array to Detect Biothreat Agents and Environmental Samples for DHS
}

\author{
Contributors: \\ Crystal Jaing \\ Shea Gardner \\ Kevin McLoughlin \\ James Thissen \\ Lawrence Livermore National Laboratory (LLNL), Livermore, CA \\ Principal Investigator and Correspondent \\ Crystal Jaing \\ 925-424-6574, jaing2@1lnl.gov \\ Paul Jackson \\ (925) 424-2729, jackson80@1lnl.gov
}

This document was prepared as an account of work sponsored by an agency of the United States government. Neither the United States government nor Lawrence Livermore National Security, LLC, nor any of their employees makes any warranty, expressed or implied, or assumes any legal liability or responsibility for the accuracy, completeness, or usefulness of any information, apparatus, product, or process disclosed, or represents that its use would not infringe privately owned rights. Reference herein to any specific commercial product, process, or service by trade name, trademark, manufacturer, or otherwise does not necessarily constitute or imply its endorsement, recommendation, or favoring by the United States government or Lawrence Livermore National Security, LLC. The views and opinions of authors expressed herein do not necessarily state or reflect those of the United States government or Lawrence Livermore National Security, LLC, and shall not be used for advertising or product endorsement purposes.

This work performed under the auspices of the U.S. Department of Energy by Lawrence Livermore National Laboratory under Contract DE-AC52-07NA27344. 


\section{SUMMARY}

The objective of this project is to provide DHS a comprehensive evaluation of the current genomic technologies including genotyping, Taqman PCR, multiple locus variable tandem repeat analysis (MLVA), microarray and high-throughput DNA sequencing in the analysis of biothreat agents from complex environmental samples. This report focuses on the design, testing and results of samples on the Census Array.

We designed a Census/Detection Array to detect all sequenced viruses (including phage), bacteria (eubacteria), and plasmids. Family-specific probes were selected for all sequenced viral and bacterial complete genomes, segments, and plasmids. Probes were designed to tolerate some sequence variation to enable detection of divergent species with homology to sequenced organisms, and to be unique relative to the human genome. A combination of "detection" probes with high levels of conservation within a family plus "census" probes targeting strain/isolate specific regions enabled detection and taxonomic classification from the level of family down to the strain. The array has wider coverage of bacterial and viral targets based on more recent sequence data and more probes per target than other microbial detection/discovery arrays in the literature. We tested the array with purified bacterial and viral DNA/RNA samples, artificial mixes of known bacterial/viral samples, spiked DNA against complex background including BW aerosol samples and soil samples, and environmental samples to evaluate the array's sensitivity and forensic capability. The data were analyzed using our novel maximum likelihood software. For most of the organisms tested, we have achieved at least species level discrimination.

\section{METHODS}

\section{Sequence analysis and microarray probe design to develop "census" array}

We included two types of probes on the "census" array: detection probes and census probes. Detection probes are conserved across multiple sequences from within a family or family-unclassified viral group, but not conserved across families or kingdoms (i.e. they are unique to a family). Such probes aim to detect known organisms or discover novel organisms that have not been sequenced but which possess some sequence homology to organisms that have been sequenced, particularly in those regions found to be conserved among previously sequenced members of that family. We have previously design a Lawrence Livermore Microbial Detection Array using this approach (1). These conserved probes may identify an organism to the level of genus or species, for example, but may lack the specificity to pin the identification down to strain or isolate. Census probes, in contrast, represent the least conserved regions, that is, the most strain or isolate specific probes. Such census probes aim to fill the goal of providing higher level discrimination/identification of known species and strains to facilitate forensic resolution, but may fail to detect novel organisms with limited homology to sequenced organisms. We included both types of probes on the census array to maximize the capability to detect both well-characterized and novel microbes and to facilitate high confidence classification at both higher (family) and lower (species and strain) taxonomic levels.

The array design process is diagrammed in Figure 1. We downloaded all sequences, including complete genomes and sequence fragments (genes, noncoding regions, etc.), 
organized by family, for all bacteria and viruses, from NCBI Genbank, Integrated Microbial Genomics (IMG) project at the Joint Genome Institute, The Comprehensive Microbial Resource (CMR) at the JC Venter Institute, and The Sanger Institute in the United Kingdom, with some additional proprietary whole-genome data from collaborators. Bacteria were those under the superkingdom Bacteria (eubacteria) taxonomy node at NCBI, and did not include the Archaea. Sequence data for complete genomes, viral segments, and plasmids was current as of August 2009, and for sequence fragments as of January 2009. Table 2 summarizes the number of families, species, genomes, and sequence fragments represented on the array. The process of downloading the sequence data into curated groups required more than a week, with automated scripts running $24 \times 7$.

Figure 1: Diagram of the census/detection array design process

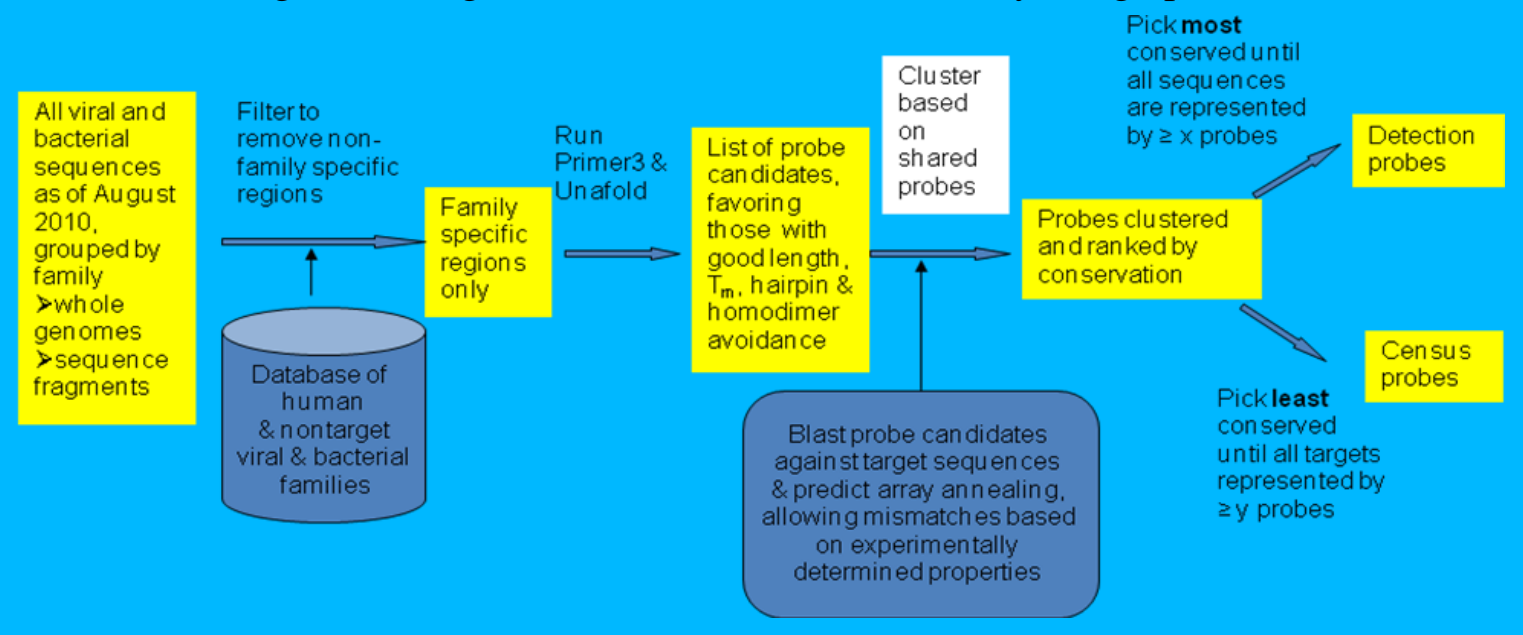

We began the array design process by identifying the family specific regions in each family. In prior work, we have found that the length of longest perfect match (PM) is a strong predictor of hybridization intensity, and that for probes at least $50 \mathrm{nt}$ long, $\mathrm{PM} \leq 20$ bp have signal less than $20 \%$ of that with a perfect match over the entire length of the probe (2). This is similar to results from a systematic study of viral probe hybridization characteristics by (3). Therefore, for each target family we eliminated regions with perfect matches to sequences outside the target family. Using the suffix array software vmatch (4), perfect match subsequences of at least $17 \mathrm{nt}$ long present in non-target viral families or $25 \mathrm{nt}$ long present in the human genome or nontarget bacterial families were eliminated from consideration as possible probe subsequences. Sequence similarity of probes to non-target sequences below this threshold was allowed, but could be accounted for using the statistical algorithm described below.

From these family-specific regions, we designed probes 50-66 bases long for one family at a time using the methods described in (2). Briefly, we generated candidate probes using MIT' s Primer3 software (5), followed by $\mathrm{T}_{\mathrm{m}}$ and homodimer, hairpin, and probetarget free energy $(\Delta \mathrm{G})$ prediction using Unafold. Candidate probes with unsuitable $\Delta \mathrm{G}^{\prime} \mathrm{s}$ or $\mathrm{T}_{\mathrm{m}}$ ' $\mathrm{s}$ were excluded as described in (2). Desirable range for these parameters was $50 \leq$ length $\leq 66, \mathrm{~T}_{\mathrm{m}} \geq 80^{\circ} \mathrm{C}, 25 \% \leq \mathrm{GC} \% \leq 75 \%, \Delta \mathrm{G}_{\text {homodimer }}=\Delta \mathrm{G}$ of homodimer formation $>15 \mathrm{kcal} / \mathrm{mol}, \Delta \mathrm{G}_{\text {hairpin }}=\Delta \mathrm{G}$ of hairpin formation $>-11 \mathrm{kcal} / \mathrm{mol}$, and $\Delta \mathrm{G}_{\text {adjusted }}$ 
$=\Delta G_{\text {complement }}-1.45 \Delta G_{\text {hairpin }}-0.33 \Delta G_{\text {homodimer }} \leq-52 \mathrm{kcal} / \mathrm{mol}$. An additional minimum sequence complexity constraint was enforced, requiring a trimer frequency entropy of at least 4.5 (calculation described below). If fewer than a minimum number of candidate probes per target sequence passed all the criteria, then those criteria were relaxed to allow a sufficient number of probes per target. To relax the criteria, first candidates that passed the primer 3 criteria but failed the Unafold filters were allowed. If no candidates passed the primer 3 criteria, then regions passing the target-specificity (e.g. family specific) and minimum length constraints were allowed.

Next, we BLASTed these candidates against the family of target sequences from which they were designed to predict the targets that should be represented by each candidate. A target was considered to be represented if a probe matched it with at least $85 \%$ sequence similarity over the total probe length, and a perfectly matching subsequence of at least 29 contiguous bases spanned the central base of the probe (it could be off center, so long as it spanned the middle position). We ranked the probe candidates by their level of conservation, that is, how many targets they were predicted to represent. From here, we followed two contrasting strategies to pick 1) detection probes, and 2) census probes.

For detection probes, we selected probes in decreasing order of the number of targets represented by that probe (i.e. probes detecting more targets in the family were chosen preferentially over those that detected fewer targets in the family).For probes that tied in the number of targets represented, a secondary ranking was used to favor probes most dispersed across the target from those probes which had already been selected to represent that target. The probe with the same conservation rank that occurs at the farthest distance from any probe already selected from the target sequence is the next probe to be chosen to represent that target.

For census probes, the process was similar except that we selected probes in increasing order of the number of targets represented by that probe (i.e. probes detecting fewer targets in the family were chosen preferentially over those that detected more targets in the family). The same criterion as described above was imposed to maximize positional dispersion of multiple probes across each target sequence. A minimum of 5 probes per target sequence were included. For sequences that diverged from other members of the family or that clustered as a highly conserved subgroup (e.g. multiple sequences from the same outbreak), the detection and census probes could be the same. Duplicate probes were removed in the final chip design.

We included 5-30 detection probes per target and 1-10 census probes per target depending on the array density. Several versions of the census and combined detection/census arrays were designed that differ in density, and thus cost. The standard census array fits on the $388 \mathrm{~K}$ NimbleGen design (Table 2). The Nimblegen $2.1 \mathrm{M}$ and Agilent $1 \mathrm{M}$ formats allowed more probes per target sequence. These higher density format arrays were not used for the NGFA-5 sample analysis. Detection probes were designed for all targets, both complete genomes and plasmids and sequence fragments. Census probes were design for all viruses, both complete and partial sequences, and for all complete bacterial genomes and plasmids. Census probes were also designed for sequence fragments for the $\sim 240$ bacterial families with less available sequence data $(<\sim 150 \mathrm{MB})$, although array density limitations did not allow us to include census probes 
for the sequence fragment data for the 32 families with the most available sequence data ( 200 MB-2.5 GB and with thousands of sequences), since those families were already so well-represented by the copious detection probes as well as census probes for the numerous complete genomes. Moreover, these partial sequences included many extremely highly conserved rRNA genes which are inappropriate for strain discrimination. Additional probes representing the partial sequences for these already heavily represented families was thought to be unnecessary for the goal of censusing for strain discrimination.

Approximately 1,000- 3,500 random negative control sequences length and GC\% matched to the target probes were included. These had no appreciable homology to known sequences based on BLAST similarity, and were used to assess background hybridization intensity. We included probes that tile across the Biowatch amplicons for the viral hemorrhagic fevers, to increase sensitivity in case the array were used to confirm a Biowatch hit for these organisms. Probes were also included to represent unpublished viral sequence fragments provided by our collaborators at the San Francisco Blood Systems Research Institute (abbreviated as SFBB for SF Blood Bank).

Table 1: Summary of sequences represented on Census array.

\begin{tabular}{|c|c|c|}
\hline Number of Targets & Virus & Bacteria \\
\hline Families & 80 & 274 \\
\hline Groups w/out Family Classification & 48 & 65 \\
\hline $\begin{array}{l}\text { Species with complete genome, plasmid, } \\
\text { or segment data }\end{array}$ & 2530 & 1290 \\
\hline $\begin{array}{l}\text { Species with any sequence data, } \\
\text { including sequence fragments }\end{array}$ & 5719 & 14765 \\
\hline Sequences Classified as to Family & 171264 & 728467 \\
\hline Sequences UnClassified as to Family & 6996 & 56251 \\
\hline $\begin{array}{l}\text { Complete genomes, segments, or } \\
\text { plasmids }\end{array}$ & 55803 & 4122 \\
\hline
\end{tabular}

Table 2: Types of microarray probes for the Standard 388K census array

\begin{tabular}{|c|c|c|}
\hline $\begin{array}{r}\text { \# of } \\
\text { Probes } \\
\end{array}$ & Probe Type & Comments \\
\hline 380088 & $\begin{array}{l}\text { Bacteria and virus census } \\
\text { and detection probes }\end{array}$ & $\begin{array}{l}\text { Census probes: } 5 \text { pps for all viral sequences } \\
\text { and bacterial whole genomes and plasmids, } 1 \\
\text { pps for bacterial sequence fragments from } \\
248 \text { families. } \\
\text { Detection probes: } 5 \text { pps for all sequences } \\
\text { (breakdown between census and detection is } \\
\text { not relevant due to overlap between these } \\
\text { sets) }\end{array}$ \\
\hline
\end{tabular}




\begin{tabular}{|r|l|l|}
\hline 1821 & $\begin{array}{l}\text { Hemorrhagic fever virus } \\
\text { Biowatch amplicons }\end{array}$ & $\begin{array}{l}\text { Tiled across amplicons with 50\% overlap } \\
\text { between probes (2x coverage) }\end{array}$ \\
\hline 1860 & SFBB sequences & $\begin{array}{l}\text { Tiled across amplicons with 0\% overlap } \\
\text { between probes (1x coverage) }\end{array}$ \\
\hline 1235 & random controls & \\
\hline 385004 & Total & \\
\hline
\end{tabular}

\section{DNA Extraction from pure bacteria and environmental samples}

2.1 DNA extraction from B. anthracis and B. thuriengiensis strains.

Genomic DNA from B. anthracis Ames, Sterne and A0382 and B.thuringiensis Israrensis HD500, kurstaki ATCC 33679, Y. pestis, F. tularensis, B. pseudomallei were obtained from LLNL collections. Genomic DNA from B. mallei, B.abortus, B. melitensis and B. suis were obtained from NBACC.

\subsection{DNA extraction from BioWatch Filters}

PSU filters from the NCR Laboratory were received from the BioWatch group at LLNL. One quarter of each filter had previously been excised at NCR, so only $3 / 4$ of each filter was available. One week of filters was collected from each season: Spring (4/20-4/26/09), Summer (7/19-7/25/09), Fall (10/25-10/31/09), and Winter (1/22/09-1/28/09). For each day, 7-11 "clean" filters were extracted (49-77 per week). Filters were determined to be "dirty" if they had an abundance of soot and dirt captured on their surface.

The 3/4 PSU filters were cut into 5 roughly equal pieces using sterile equipment. Up to 24 filters were placed into a $50 \mathrm{~mL}$ conical tube. $30 \mathrm{~mL}$ of $100 \mathrm{mM}$ phosphate buffer $(\mathrm{pH}$ $7.4), 0.05 \%(\mathrm{v} / \mathrm{v})$ Tween 80 was added to each $50 \mathrm{~mL}$ tube. The conical tubes were vortexed for 30 seconds and placed on a rocking shaker for 15 minutes. The 30 second vortexing and 15 min shaking was repeated an additional 3 times for a total of 1 hour of washing. The filters were removed from the tube and remaining solution was centrifuged at $3200 \times \mathrm{g}$ for 30 minutes at $5^{\circ} \mathrm{C}$. Following centrifugation, the supernatant was removed and discarded.

To complete the DNA purification, components of the UltraClean Soil DNA Isolation Kit \#12800 from MoBio (Carlsbad, CA) were utilized. The remaining pellet was resuspended with the following solutions added in this order: $100 \mu \mathrm{L}$ TE buffer, $350 \mu \mathrm{L}$

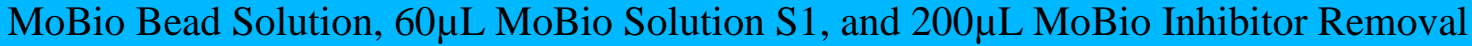
Solution. A $2 \mathrm{~mL}$ screw cap tube was loaded with $500 \mathrm{mg}$ each of 106 and $500 \mathrm{~mm}$ zirconia/silica beads. The entire $700 \mu \mathrm{L}$ of resuspended pellet was added to the $2 \mathrm{~mL}$ bead tube. The samples were bead-beated at max speed for 2 minutes. Following beadbeating, the tubes were centrifuged at 10,000 $\times \mathrm{g}$ for 30 seconds. The entire supernatant $(\sim 450 \mu \mathrm{L})$ was transferred to a sterile $2 \mathrm{~mL}$ tube for further extraction.

To the supernatant, $250 \mu \mathrm{L}$ of MoBio Solution S2 was added, vortexed for 5 seconds, and incubated at $4^{\circ} \mathrm{C}$ for 5 minutes. Following incubation the samples were centrifuged for 1 minute at 10,000 $\times \mathrm{g}$ and the supernatant transferred to a clean $2 \mathrm{~mL}$ tube. 2 volumes $(\sim 1.3 \mathrm{~mL})$ of MoBio Solution S3 was added to the supernatant and vortexed for 5 seconds. The vortexed solution was added in $700 \mu \mathrm{L}$ aliquots, until the entire sample is processed, to a MoBio spin filter and centrifuged for 1 minute at 10,000 $x \mathrm{~g}$ and the flow- 
through discarded. The spin filter was washed 3 times by adding $300 \mu \mathrm{L}$ MoBio Solution $\mathrm{S} 4$, centrifuged for 30 seconds at 10,000 $x \mathrm{~g}$, and the flow-through discarded.

The spin filter was centrifuged an additional 1 minute at $10,000 \times g$ to dry the filter. The filter was placed in a new $2 \mathrm{~mL}$ collection tube and $50 \mu \mathrm{L}$ of MoBio Solution S5 was added to the membrane. The sample was centrifuged at 10,000 $x \mathrm{~g}$ for 30 seconds and the eluted DNA was retained. The multiple elutions for each season were combined into one large volume. Samples were speed-vacced to $\sim 50 \%$ of the starting volume in order to increase the DNA concentration. DNA concentration was determined by the Invitrogen Qubit fluorometer (Carlsbad, CA).

\subsection{DNA Extraction from Soil}

Soil was collected in the downtown areas of both Oakland, CA and San Francisco, CA. Four samples were collected in each city at various sites. Samples were extracted using the MoBio UltraClean Soil DNA Isolation Kit \#12800. The manufacturer's Alternative Protocol (For Maximum Yields) was followed for this work. The only deviation from the protocol was to wash twice (Step 15) with Solution S4 instead of just once as the protocol stated.

Following extraction, 1ng of each extracted DNA was used in a Real-Time PCR assay to test for inhibition. All samples showed a high level of inhibition of PCR. Based on this each extracted DNA was re-extracted starting from Step 12 of the MoBio Alternative Protocol. This additional extraction is intended to remove additional humic acid. DNA concentration was determined by the Invitrogen Qubit fluorometer.

2.4 DNA Extraction from EPA gauze wipes Gauze wipes were obtained from a group at LLNL that conducted tests with the EPA. Wipes were used to wipe dirty surfaces indoors and were then inoculated with $6.3 \times 10^{7}$ CFU of B. thuringiensis kurstaki spores. Following inoculation, DNA was extracted from the wipes using the Promega Blood Extraction Kit (Madison, WI) according to manufacturer's instructions. After extraction, $5.0 \times 10^{4} \mathrm{CFU}$ were amplified and labeled following the procedure in Section 3 below.

2.5 Bacillus anthracis Ames DNA spiked in environmental samples

B. anthracis Ames DNA was acquired from the select agent laboratory within LLNL. Sterility test was performed to ensure the DNA is sterile before the DNA was transferred to our laboratory. DNA was quantified using the Invitrogen Qubit fluorometer and copy number was determined. Six concentrations of $B$. anthracis Ames DNA were made in 10 fold serial dilutions from 1-100,000 copies. Each concentration was mixed with $100 \mathrm{pg}$ of extracted DNA from the Spring NCR filters for the aerosol spike experiments or $1 \mathrm{ng}$ extracted DNA from the combination of soil from Oakland and San Francisco for the soil spike experiments.

\section{Microarray Processing}

An overview of the microarray process is shown in Figure 2.

\subsection{Whole Genome Amplification and Purification}


The environmental BioWatch filter samples, EPA wipe samples and B. anthracis Ames spiked samples were amplified using the Qiagen REPLI-g Midi Kit \#150043 (Valencia, CA). This kit is intended to provide uniform whole genome amplification using Multiple Displacement Amplification. Each copy number dilution of B. anthracis DNA spiked in either 1ng of soil or $100 \mathrm{pg}$ of aerosol DNA was amplified using this kit according to manufacturer's instructions. Samples were allowed to amplify for 16 hours at $30^{\circ} \mathrm{C}$. Amplified samples were purified using the Qiagen Qiaquick PCR Purification Columns \#28106 according to manufacturer's instructions. Samples were eluted in $40 \mu \mathrm{L}$ of Buffer EB from the Qiagen kit.

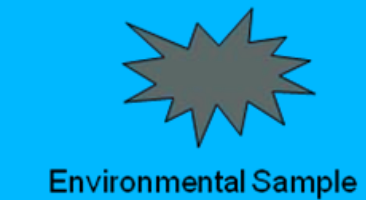

歪

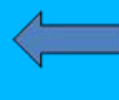

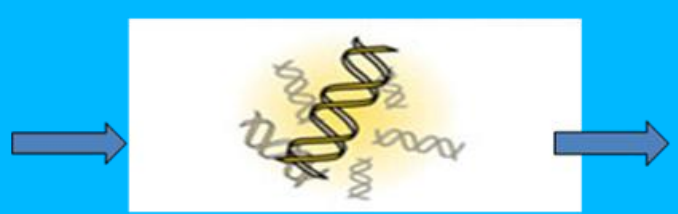

Isolate DNA/RNA Amplification if needed

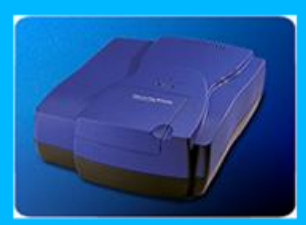

Detect signal on fluorescent scanner

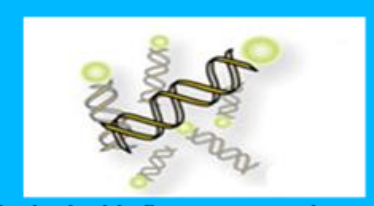

Label with fluorescent dye

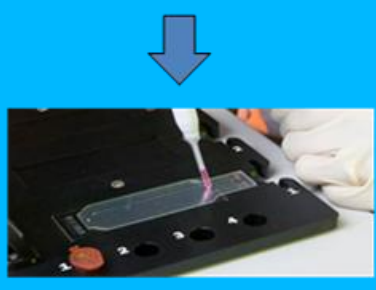

Hybridize sample on array

Figure 2. Microarray hybridization process

\subsection{Microarray hybridization}

The entire $40 \mu \mathrm{L}$ of amplified product was fluorescently labeled using the Roche NimbleGen One-Color DNA Labeling Kit \#05223555001 (Madison, WI) according to the recommended protocols. The DNA was purified after labeling, and hybridized using the NimbleGen Hybridization Kit (Cat. 05583683001) to the LLNL Census Array according to manufacturers' instructions. The microarrays were allowed to hybridize for 17 hours and washed using the NimbleGen Wash Buffer Kit \#05584507001 according to manufacturer's instructions. Microarrays were scanned on an Axon GenePix 4000B 5 $\mu \mathrm{m}$ scanner from Molecular Devices (Sunnyvale, CA). The scanned tif image files were aligned using the NimbleScan Version 2.4 software and pair text files were exported for data analysis.

\section{Microarray data Analysis}

A maximum likelihood analysis method was used to analyze the microbial hits from samples hybridized to the array. The method was recently published in (1). An example of the analysis results is shown in Figure 3 where $B$. thuringiensis kurstaki was run on the Census Array. The right-hand column of bar graphs shows the unconditional and conditional log-odds ratios for each target genome listed at right. The unconditional logodds is the larger of the two scores; thus the lighter and darker-colored portions represent the unconditional and conditional scores respectively. Targets are color-coded and grouped by taxonomic family, according to the legend at bottom; they are listed within families in decreasing order of conditional log-odds ratio scores. Targets predicted as 
likely to be present are indicated in red text. The vertical orange dashed line marks 0 on the log-odds ratio scale.

The left-hand column of bar graphs shows the expectation (mean) values of the numbers of probes expected to be present given the presence of the corresponding target genome. The larger "expected" score is obtained by summing the conditional detection probabilities for all probes; the smaller "detected" score is derived by limiting this sum to probes that were actually detected. Because probes often cross-hybridize to multiple related genome sequences, the numbers of "expected" and "detected" probes often greatly exceed the number of probes that were actually designed for a given target organism.

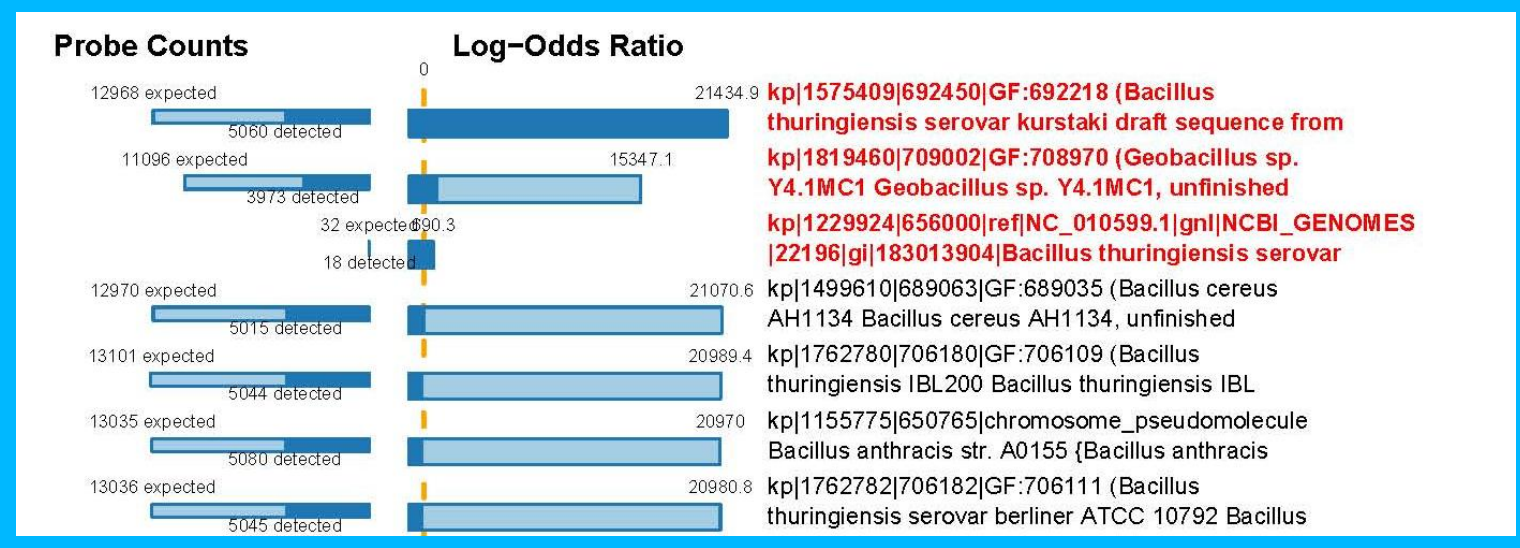

Figure 3. Census Chip result for B.thurigiensis kurstaki

\section{RESULTS}

\section{Hybridization of B. anthracis and B. thuriengiensis DNAs on the Census Array.}

The primary goal of array analysis was to identify, for each sample, the organism(s) with known genomic sequence that best explains the pattern of bright (detected) and dark (undetected) probes on the array. Some of the organisms we tested have not been sequenced; for these, our measure of success is whether the analysis identifies the correct species (when other strains of the same species have been sequenced). We isolated genomic DNAs from $B$. anthracis Ames, Sterne and A0382 and DNAs from B.thuringiensis Israrensis HD500, kurstaki ATCC 33679. The DNAs were hybridized to the Census Array. The data is shown in Table 3. The Census Array corrected identified each of the DNA to at least the species level. For $B$. thuringiensis, the identification was at the strain level. $B$. anthracis strains were not correctly detected to the strain level. Our analysis algorithm takes into account the combined scores of probe hits to targets. When there is a genomic sequence glued from both draft genomes and plasmids such as the $B$. anthracis A0155, the algorithm assigns a higher score due to the longer length of the sequence. This issue is being addressed by our team so the probe hit scores can be assigned based on the length of the targets, instead of giving higher scores to longer sequences. 
Table 3. Census Array results from B. anthracis, B. thuringiensis and F. tularensis DNAs

\begin{tabular}{|c|c|}
\hline DNA hybridized on array & Census Array top hit \\
\hline B. anthracis Ames & $\begin{array}{l}\text { B. anthracis A0155, } \\
\text { B. anthracis Sterne }\end{array}$ \\
\hline B. anthracis Sterne & B. anthracis A0155 \\
\hline B. anthracis $\mathrm{A} 0382$ & B. anthracis $\mathrm{A} 0155$ \\
\hline B. thuringiensis Israelensis HD500 & B. thuringiensis IBL4222 \\
\hline $\begin{array}{l}\text { B. thuringiensis Kurstaki ATCC } \\
33679\end{array}$ & B. thuringiensis kurstaki \\
\hline F. tularensis holarctica LVS & F. tularensis LVS \\
\hline
\end{tabular}

\section{Evaluation of mixtures of biothreat bacterial samples}

Genomic DNAs from B. anthracis Ames, Y. pestis CO92, F. tularensis LVS, Brucella abortis, B. pseudomallei PHLS9 and B. mallei 23344 were mixed together in one single sample and hybridized on the $388 \mathrm{~K}$ census array. The results are shown in Table 4.

All six bacterial species were correctly identified except for B. mallei which was not detected. It is not clear why this species was not detected in this experiment. F. tularensis LVS was correctly identified at the strain level.

Table 4. Census Array results from a mixture of bacterial DNAs

\begin{tabular}{|c|c|c|c|}
\hline $\begin{array}{l}\text { Actual } \\
\text { Species }\end{array}$ & $\begin{array}{l}\text { Actual } \\
\text { Strain }\end{array}$ & $\begin{array}{l}\text { Predicted } \\
\text { Species }\end{array}$ & $\begin{array}{l}\text { Predicted } \\
\text { strain }\end{array}$ \\
\hline B. anthracis & Ames & B. anthracis & A0193 \\
\hline Y. pestis & $\mathrm{CO} 92$ & Y.pestis & PEXU2 \\
\hline F. tularensis & holarctica LVS & F. tularensis & LVS \\
\hline B.pseudomallei & PHLS9 & B.pseudomallei & E208 \\
\hline $\begin{array}{l}\text { B. mallei } \\
\text { Brucella }\end{array}$ & $\begin{array}{l}\text { ATCC } 23344 \\
\text { abortis }\end{array}$ & $\begin{array}{l}\text { ND } \\
\text { Brucella }\end{array}$ & $\begin{array}{l}N D \\
\text { melitensis }\end{array}$ \\
\hline
\end{tabular}

\section{Determination of the limit of detection of the Census Array using B. anthracis Ames spiked into BioWatch aerosol samples.}

We performed limit of detection testing of the Census Array using serially diluted $B$. anthracis Ames spiked into BioWatch aerosol filter extracts that have been subjected to whole genome amplification. Duplicate experiments were run to ensure repeatability and data consistency. 1, 10,100,1,000,10,000, and 100,000 copies of B. anthracis Ames were tested. Table 5 below shows results of the census array at each of the $B$. anthracis DNA concentration. When 10 copies of $B$. anthracis DNA were spiked into aerosol sample, only one of the two replicate experiments detected $B$. anthracis, suggesting that there were not enough probes specific to $B$. anthracis detected at this concentration. This experiment suggested that our detection limit for $B$. anthracis Ames could be in the range between 10-100 copies when the DNA was spiked into $100 \mathrm{pg}$ of aerosol DNA sample. 
Table 5. Limit of detection of B. anthracis Ames DNA spiked in Biowatch aerosol samples.

\begin{tabular}{|c|c|c|c|c|c|c|}
\hline $\begin{array}{c}\text { Amount aerosol } \\
\text { filter DNA }\end{array}$ & $100 \mathrm{pg}$ & $100 \mathrm{pg}$ & $100 \mathrm{pg}$ & $100 \mathrm{pg}$ & $100 \mathrm{pg}$ & $100 \mathrm{pg}$ \\
\hline $\begin{array}{c}\text { Amount B. } \\
\text { anthracis DNA }\end{array}$ & $560 \mathrm{pg}$ & $56 \mathrm{pg}$ & $5.6 \mathrm{pg}$ & $560 \mathrm{fg}$ & $56 \mathrm{fg}$ & $5.6 \mathrm{fg}$ \\
\hline $\begin{array}{c}\text { B. anthracis } \\
\text { DNA Copy \# }\end{array}$ & $\begin{array}{c}100,000 \\
\text { copies }\end{array}$ & $\begin{array}{c}10,000 \\
\text { copies }\end{array}$ & $\begin{array}{c}1000 \\
\text { copies }\end{array}$ & $\begin{array}{c}100 \\
\text { copies }\end{array}$ & $\begin{array}{c}10 \\
\text { copies }\end{array}$ & $\begin{array}{c}1 \\
\text { copy }\end{array}$ \\
\hline $\begin{array}{c}\text { \% BA DNA in } \\
\text { aerosol DNA }\end{array}$ & $98.2 \%$ & $35.9 \%$ & $5.3 \%$ & $0.56 \%$ & $0.06 \%$ & $0.006 \%$ \\
\hline $\begin{array}{c}\text { Census Array } \\
\text { top hit }\end{array}$ & $\begin{array}{c}\text { B. } \\
\text { anthracis }\end{array}$ & $\begin{array}{c}\text { B. } \\
\text { anthracis }\end{array}$ & $\begin{array}{c}\text { B. } \\
\text { anthracis }\end{array}$ & $\begin{array}{c}\text { B. } \\
\text { anthracis }\end{array}$ & $\begin{array}{c}\text { B. } \\
\text { anthracis }\end{array}$ & $\begin{array}{c}\text { Not } \\
\text { detected }\end{array}$ \\
\hline
\end{tabular}

\section{Determination of the limit of detection of the Census Array using B. anthracis Ames spiked into soil samples.}

We performed as similar limit of detection testing of the Census Array using serially diluted B. anthracis Ames spiked into soil extracts that have been subjected to whole genome amplification. The soils were collected locally in San Francisco and Oakland. Duplicate experiments were run to ensure repeatability and data consistency. 1, 10, 100, 1,000, 10,000, and 100,000 copies of B. anthracis Ames were tested. Table 6 below shows results of the census array at each of the $B$. anthracis DNA concentration. When 100 copies of $B$. anthracis DNA were spiked into soil sample, only one of the two replicate experiments detected $B$. anthracis, suggesting that there were not enough probes specific to $B$. anthracis detected at this concentration. This experiment suggested that our detection limit for $B$. anthracis Ames could be in the range between 100-1000 copies when the DNA was spiked into $1 \mathrm{ng}$ of soil DNA sample.

Table 6. Limit of detection of B. anthracis Ames DNA spiked in soil samples.

\begin{tabular}{|l|l|l|l|l|l|l|}
\hline $\begin{array}{l}\text { Amount soil } \\
\text { DNA }\end{array}$ & $1 \mathrm{ng}$ & $1 \mathrm{ng}$ & $1 \mathrm{ng}$ & $1 \mathrm{ng}$ & $1 \mathrm{ng}$ & $1 \mathrm{ng}$ \\
\hline $\begin{array}{l}\text { Amount B. } \\
\text { anthracis DNA }\end{array}$ & $560 \mathrm{pg}$ & $56 \mathrm{pg}$ & $5.6 \mathrm{pg}$ & $560 \mathrm{fg}$ & $56 \mathrm{fg}$ & $5.6 \mathrm{fg}$ \\
\hline $\begin{array}{l}\text { B. anthracis } \\
\text { DNA Copy \# }\end{array}$ & $\begin{array}{l}100,000 \\
\text { copies }\end{array}$ & $\begin{array}{l}10,000 \\
\text { copies }\end{array}$ & $\begin{array}{l}1000 \\
\text { copies }\end{array}$ & $\begin{array}{l}100 \\
\text { copies }\end{array}$ & $\begin{array}{l}10 \\
\text { copies }\end{array}$ & \begin{tabular}{l} 
copy \\
\hline $\begin{array}{l}\text { \% BA DNA in } \\
\text { soil DNA }\end{array}$
\end{tabular} \\
\hline $\begin{array}{l}\text { Census Array } \\
\text { top hit }\end{array}$ & $\begin{array}{l}\text { B. } \\
\text { anthracis }\end{array}$ & $\begin{array}{l}\text { B. } \\
\text { anthracis }\end{array}$ & $\begin{array}{l}\text { B. } \\
\text { anthracis }\end{array}$ & $\begin{array}{l}\text { B. } \\
\text { anthracis }\end{array}$ & $\begin{array}{l}\text { Not } \\
\text { detected }\end{array}$ & $\begin{array}{l}\text { Not } \\
\text { detected }\end{array}$ \\
\hline
\end{tabular}

\section{Analysis of DNA samples from previous DHS or EPA exercises to release and detect $B$. thuringiensis spores.}

Aerosol filters were collected during the days when B. thuringiensis kurstaki was sprayed to control Gypsy Moth in a DHS surrogate study. Gauge wipes were used to wipe dirty indoor surfaces and inoculated with B. thuringiensis kurstaki spores in an exercise conducted with EPA. Genomics DNAs were extracted from filters or wipe samples and 
run on the Census Array. The results are shown in Table 7. We were able to positively identify $B$. thuringiensis kurstaki using the Census Array from both the air filter samples and the gauge wipe samples.

Table 7. Detection of $B$. thuringiensis from environmental air or wipe samples.

\begin{tabular}{|l|l|l|}
\hline Sample & $\begin{array}{l}\text { Air filters collected around Gypsy } \\
\text { Moth control study }\end{array}$ & $\begin{array}{l}\text { Gauge wipes collected during } \\
\text { an EPA exercise }\end{array}$ \\
\hline $\begin{array}{l}\text { B. thuringensis kurstaki } \\
\text { specific Taqman asay }\end{array}$ & Average $\mathrm{Ct}=22.77 \pm 0.27$ & Average $\mathrm{Ct}=30.70 \pm 0.31$ \\
\hline Census array top hits & $\begin{array}{l}\text { B. thuringiensis kurstaki } \\
\text { Bacillus megaterium QM B1551 } \\
\text { Magnetospirillum Magnetotacticum } \\
\text { MS-1 } \\
\text { Thioalkalivibrio sp. } \\
\text { Ralstonia pickettii } 12 \mathrm{D}\end{array}$ & $\begin{array}{l}\text { B. thuringiensis kurstaki } \\
\text { Magnetospirillum } \\
\text { magnetacticum MS }-1 \\
\text { Tlkalimnicola ehrlichei } \\
\text { Tolumonas auensis DSM }\end{array}$ \\
\hline
\end{tabular}

\section{REFERENCES}

1. Gardner, S., Jaing, C., McLoughlin, K. and Slezak, T. (2010) A Microbial Detection Array (MDA) for viral and bacterial detection. BMC Genomics, 11, 668doi:610.1186/1471-2164-1111-1668.

2. Jaing, C., Gardner, S., McLoughlin, K., Mulakken, N., Alegria-Hartman, M., Banda, P., Williams, P., Gu, P., Wagner, M., Manohar, C. et al. (2008) A Functional Gene Array for Detection of Bacterial Virulence Elements. PLoS ONE, 3, e2163.

3. Wong, C., Heng, C., Wan Yee, L., Soh, S., Kartasasmita, C., Simoes, E., Hibberd, M., Sung, W.-K. and Miller, L. (2007) Optimization and clinical validation of a pathogen detection microarray. Genome Biology, 8, R93.

4. Giegerich, R., Kurtz, S. and Stoye, J. (2003) Efficient implementation of lazy suffix trees. Software-Practice and Experience, 33, 1035-1049.

5. Rozen, S. and Skaletsky, H. (2000) In Krawetz, S. and Misener, S. (eds.), Bioinformatics Methods and Protocols: Methods in Molecular Biology Humana Press, Totowa, NJ, pp. 365-386. 